\title{
Peripheral Cemento-Ossifying Fibroma in an Adolescent: A Case Report
}

\author{
Jaiti Uppal ${ }^{1}$, ND Gupta ${ }^{1}$ and Himanshu Trivedi ${ }^{2 *}$ \\ ${ }^{1}$ Aligarh Muslim university, India \\ ${ }^{2}$ Department of periodontics and public health dentistry, Aligarh Muslim University, India \\ *Corresponding author: Himanshu Trivedi, Department of periodontics and public health dentistry, Aligarh Muslim University, Aligarh, UP, India
}

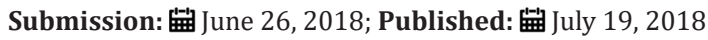

\begin{abstract}
Peripheral ossifying fibroma is a reactive lesion of the gingiva presenting as a firm and nodular mass more commonly in the anterior maxilla in adolescent females. It originates from the connective tissue of gingiva or periodontal ligament and presents as a benign, slow growing, painless mass that is relatively less common, contributing to $8 \%$ of the gingival enlargements. Diagnosis is confirmed by histopathology and treatment includes surgical excision. Recurrence rate has been reported to be 8\%-20\% and may be due to the remnants of pathologic tissue after excision. This case report presents a classical case of peripheral cement-ossifying fibroma in a 17yr old female in maxillary incisor-cuspid region which was treated by local excision and debridement.
\end{abstract}

\section{Introduction}

Fibromas are benign tumours arising from the connective tissue. They are common growths seen in the oral cavity presenting as different pathological entities such as irritational fibroma, odontofenic fibroma, central and peripheral ossifying fibroma, cement-ossifying fibroma [1]. PCOF is more of a reactive lesion rather than benign tumour, owing to local irritation by factors such as microorganisms, plaque, calculus, trauma, restorative materials and ill fitting dental appliances/prosthesis [2,3].

\section{Case Report}

A 17 year old female reported to the department of Periodontics and community dentistry, Dr. Z. A. Dental College, Aligarh with the chief complain of swollen gums in right upper front jaw region since 3 months and difficulty in biting since 1 month. She gave the history of painless small nodule appearing on the gum on the palatal side that gradually enlarged to form a mass which interfered with occlusion. The patient started biting from left side since 2 weeks. There was no significant medical and dental history and no history of trauma or any deleterious oral habits. Oral hygiene was fair and she maintained using toothbrush and dentifrice in a horizontal stroke method once daily.

On extra oral examination, face was mesoprosopic, bilaterally symmetrical with a convex profile and incompetent lips. The regional lymph nodes were non palpable and non tender. Intraoral examination revealed solitary, non tender, reddish pink growth with lobulated surface on palatal gingival of maxillary central and lateral incisors. Local irritating factors like plaque and sub gingival calculus were present. Palatal pocket of $6 \mathrm{~mm}$ was present irt\#11\#12 (FDI tooth notation) with gingival margin coronal to CEJ. Palpation revealed firm, fibrotic consistency with exudation from the pocket on pressure. There was pathological migration of \#12 in labial direction and the tooth was grade I mobile and tender on percussion (Figure 1).

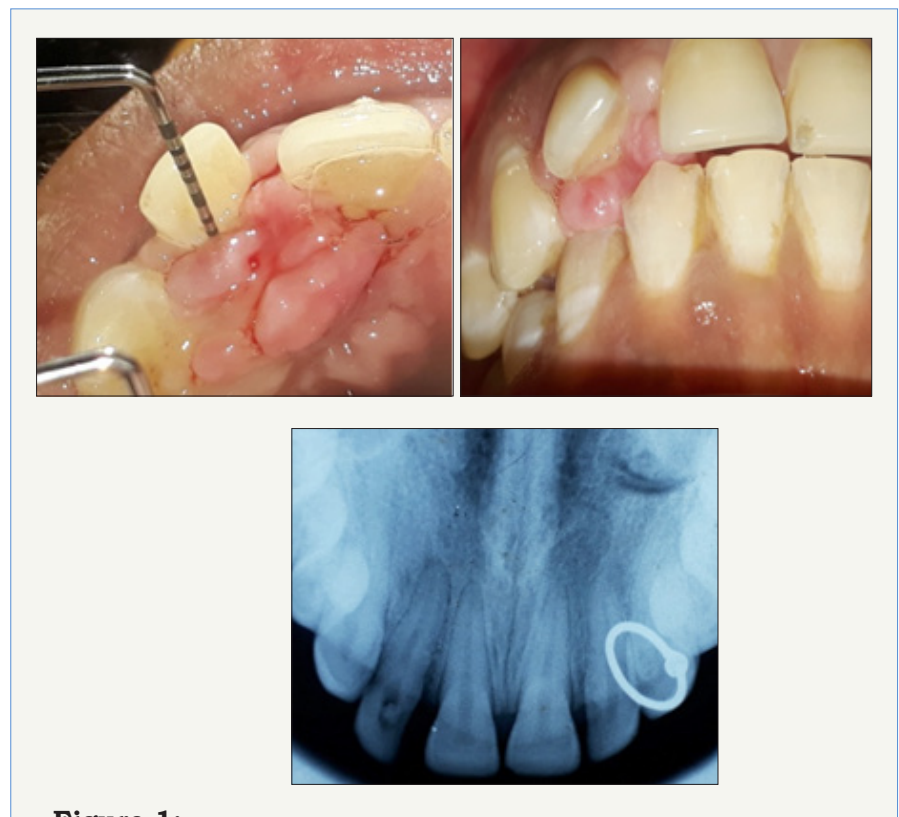

Figure 1: 


\section{Investigations}

\section{Radiographic examination}

IOPA revealed loss of interdental bone in the maxillary right anterior region and widening of periodontal ligament space irt\#12 with developing periapical radiolucency. Blood examination included haemoglobin, bleeding time, clotting time and complete blood count which were found within normal limits.

\section{Diagnosis}

Provisional diagnosis of PCOF was made based on the history and clinical features. Differential diagnosis included pyogenic granuloma peripheral giant cell granuloma and fibrous hyperplasia.

\section{Treatment Plan}

\section{Phase-I therapy}

Sub gingival scaling using and root planning using ultrasonic scalar and manual curettes was performed to remove the debris, plaque and calculus and oral hygiene instructions were given to Gross Examination of Biopsy Specimen the patient for the inflammatory component to subside. Local excision under LA and biopsy was planned followed by endodontic treatment of the non vital tooth \#12 two weeks after the surgery.

\section{Surgical Procedure}

After achieving adequate anaesthesia with $2 \%$ xylocaine and 1:80,000 adrenalines, internal bevel incision was given with \#15 BP blades apical to the base of pocket on the palatal aspect of incisors following the scalloped contour of teeth. 4-0 silk suture was inserted to engage the growth and lift it up after which the entire mass was excised from its base. The underlying bone was debrided of the granulation tissue and the inner surface of interdental gingiva wrt \#11 and \#13 was curetted to remove the pocket lining both labially and palatly. The surgical site was irrigated with betadine and haemostasis was achieved by placing gel sponge and pressure pack on the surgical site. Coe pack was placed for 15 days and the patient was given post operative instructions. Analgesic and antibiotic medications were prescribed for 5 days.
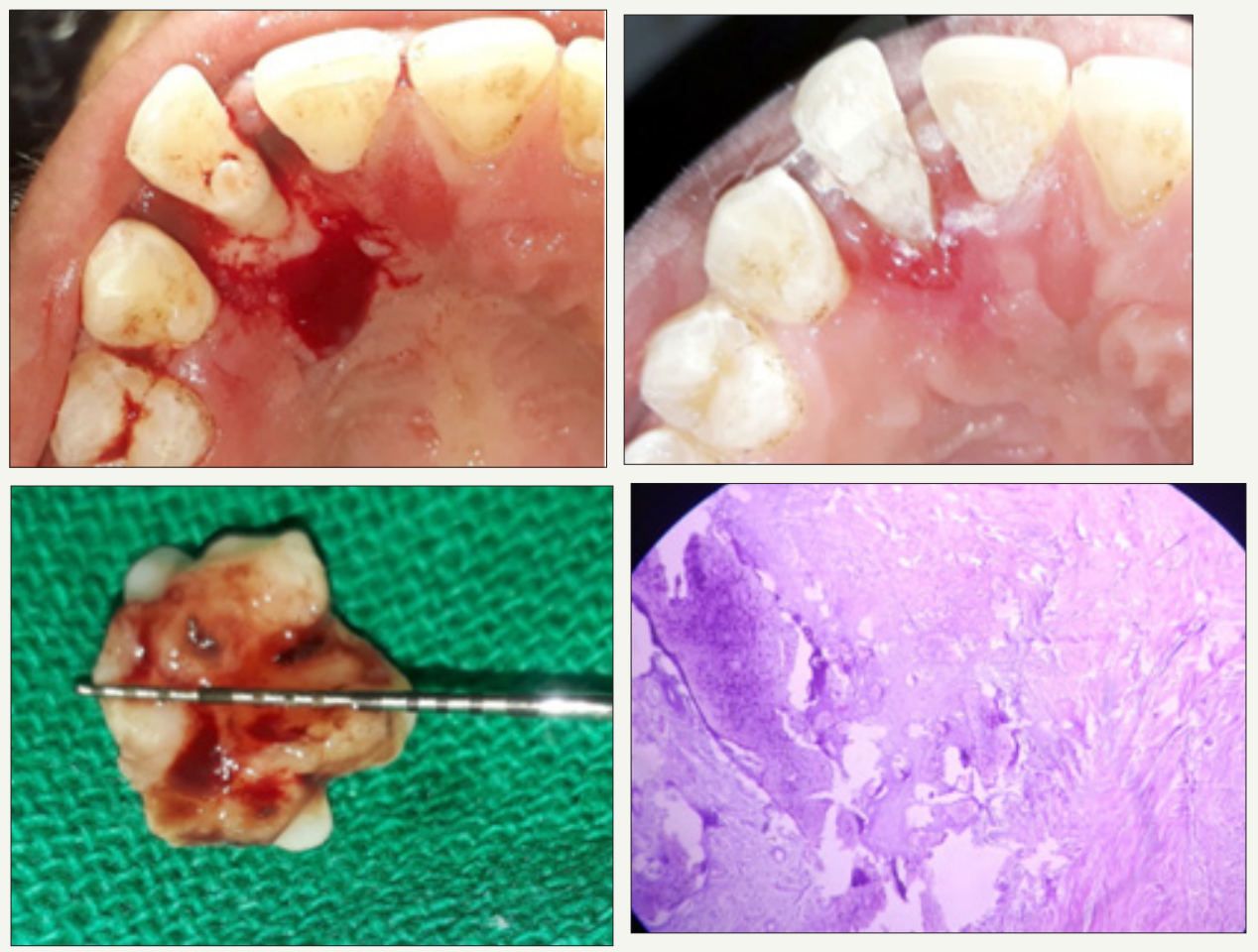

Figure 2:

On macroscopic examination, the biopsy yielded a $12 \mathrm{mmX} 10 \mathrm{~mm}$ large pale pink mass with lobulated and corrugated surface and firm-rubbery consistency (Figure 2).

\section{Microscopic Examination}

The specimen was preserved in $10 \%$ formalin and sent to the department of Pathology, JNMC, AMU, and Aligarh for histopathology examination. It revealed $\mathrm{H} \& \mathrm{E}$ stained section of stratified squamous epithelium lined tissue showing sub epithelial fibrous tissue proliferation along with immature bony tissue formation and focal areas showing cementum like material (psammomatous pattern) in the fibrous stroma. Lymphoplasmacytic infiltration of connective tissue was present. The features were suggestive of peripheral cemento-ossifying fibroma.

\section{Follow Up}

The patient reported 1 week after the surgery with spontaneous and sharp shooting pain in tooth \#12.Endodontic therapy was 
initiated, access opening was made and pus was drained from the canal by copious irrigation with normal saline, sodium hypochlorite and hydrogen peroxide. The patient returned for pack removal 15days after the surgery. The surgical site showed uneventful healing with epithelium covering the bone. Irrigation was done with betadine and patient was motivated and reinforced for performing meticulous plaque control.

\section{Discussion}

Peripheral ossifying fibroma is a reactive lesion of the gingiva presenting as a firm and nodular mass more commonly in the anterior maxilla in adolescent females. It is thought to arise from the connective tissue of gingival, periodontal ligament or periosteal tissue of the alveolar bone [4]. It usually presents as a benign, slow growing, painless mass that is relatively less common, contributing to $9.6 \%$ of the gingival enlargements [5]. It may enlarge to sufficient sizes causing facial deformity or pathological migration of teeth with difficulty in occlusion [6-8].

Radiographic changes may not always be present, sometimes it may appear as superficial erosion of bone and interdental bone loss may be present. Since there are many confusions regarding nomenclature of this lesion, the 1992 WHO classification has grouped under one category histologically different lesions (i.e ossifying and cementifying fibomas) that may present in a similar manner clinically and radiographically [9]. Apart from its clinical features, diagnosis is confirmed by histopathology. Differential diagnosis includes peripheral giant cell granuloma, pyogenic granuloma, irritational fibroma, osteoid osteoma. Treatment includes surgical excision with curettage of the adjoining tissues to remove all tumor foci [10]. The overall prognosis is excellent if properly managed with regular recalls [11]. Recurrence rate has been reported to be $8 \%-20 \%$ and may be due to the remnants of pathologic tissue after excision [1,2]. Any underlying irritating factor/trauma must be eliminated and patients must be advised to maintain best possible oral hygiene to prevent recurrence of tumor This case report, presented all salient features of PCOF including age, site, gender predilection, pathological migration, gross and microscopic features and radiographic appearance of interdental bone loss. The definitive treatment included surgical excision, thorough debridement and endodontic treatment of involved tooth to get a predictable result. The patient is symptom free for 6 months with no complain of recurrence.

\section{References}

1. Bhaskar SN, Jacoway JR (1966) Peripheral fibroma and peripheral fibroma with calcification: report of 376 cases. The Journal of the American Dental Association 73(6): 1312-1320.

2. Eversole LR, Rovin S (1972) Reactive lesions of the gingiva. Journal of Oral Pathology \& Medicine 1(1): 30-38.

3. Gardner DG (1982) The peripheral odontogenic fibroma: An attempt at clarification. Oral Surg Oral Med Oral Pathol 54(1): 40-48.

4. Kendrick F, Waggoner WF (1996) Managing a peripheral ossifying fibroma. ASDC Journal of Dentistry for Children 63(2):135-138.

5. Delbem AC, Cunha RF, Silva JZ, Soubhia AM (2008) Peripheral CementoOssifying Fibroma in child. A follow-up of 4 years. Report of a case. Eur J Dent 2(2): 134-137

6. Poon CK, Kwan PC, Chao SY (1995) Giant peripheral ossifying fibroma of the maxilla: Report of a case. Journal of Oral and Maxillofacial Surgery 53(6): 695-698.

7. Kenney JN, Kaugars GE, Abbey LM (1989) Comparison between the peripheral ossifying fibroma and peripheral odontogenic fibroma. Journal of Oral and Maxillofacial Surgery 47(4): 378-382.

8. Mesquita RA, Orsini SC, Sousa M, Araujo NS (1998) Proliferative activity in peripheral ossifying fibroma and ossifying fibroma. J Oral Pathol Med 27(2): 64-67.

9. Gondivkar SM, Gadbail AR, Chole R, Parikh RV, Balsaraf S (2011) Ossifying fibroma of the jaws: Report of two cases and literature review. Oral Oncol 47(9): 804-809.

10. Mishra AK, Maru R, Dhodapkar SV, Jaiswal G, Kumar R, et al. (2013) Peripheral cemento-ossifying fibroma: A case report with review of literature. World J Clin Cases 1(3): 128-133.

11. Waldron CA (1993) Fibro-osseous lesions of the jaws. J Oral Maxillofac Surg 51(8): 828-835.
Creative Commons Attribution 4.0 International License

For possible submissions Click Here
Submit Article

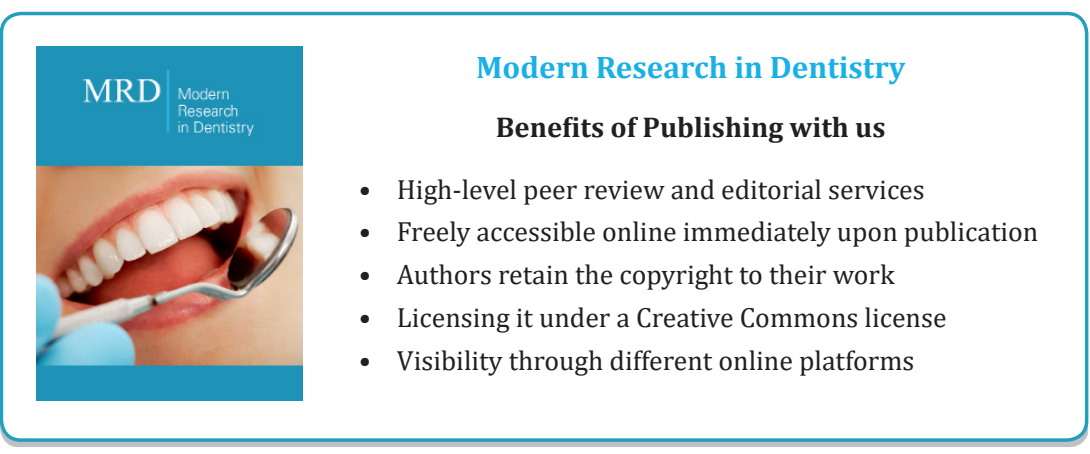

